\title{
Article
}

\section{'Hard to reach' parents but not hard to research: a critical reflection of gatekeeper positionality using a community-based methodology}

Wilson, Suzanne

Available at http://clok.uclan.ac.uk/28720/

Wilson, Suzanne ORCID: 0000-0002-7021-8967 (2020) 'Hard to reach' parents but not hard to research: a critical reflection of gatekeeper positionality using a community-based methodology. International Journal of Research \& Method in Education, 43 (5). pp. 461-477. ISSN 1743-727X

It is advisable to refer to the publisher's version if you intend to cite from the work. http://dx.doi.org/10.1080/1743727X.2019.1626819

For more information about UCLan's research in this area go to http://www.uclan.ac.uk/researchgroups/ and search for <name of research Group>.

For information about Research generally at UCLan please go to http://www.uclan.ac.uk/research/

All outputs in CLoK are protected by Intellectual Property Rights law, including Copyright law. Copyright, IPR and Moral Rights for the works on this site are retained by the individual authors and/or other copyright owners. Terms and conditions for use of this material are defined in the policies page. 


\title{
'Hard to Reach' Parents but not Hard to Research: A Critical Reflection of Gatekeeper Positionality using a Community Based Methodology
}

\begin{abstract}
Conducting research with under-represented, overlooked and service resistant groups poses challenges but can lead to valuable discoveries that inform the development of policy or practice. In this paper, a reflective account of a community-based methodology will be provided which targeted families in poverty who did not engage with the school system. The research discussed provides a phenomenological understanding of how these parents perceived their role in their child's education, and what challenges they felt they faced, both at home and in school. This community-based methodology proved effective in recruiting and obtaining data from five focus groups $(n=27)$ and a series of in-depth interviews $(n=50)$. The perceived positionality of the gatekeeper is discussed, explained using Tajfel and Turner's social identity theory (1979), with particular focus on in-group/out-group identity perceptions. The efficacy of the strategies used are discussed and recommendations for a community-based methodology for educational research is provided.
\end{abstract}

Keywords: hard-to-reach, parental engagement, community, qualitative methods

\section{Explaining Inequalities in Accessing Participation in Research}

The importance of parental engagement in education is well documented (Sammons, Toth and Sylva, 2016; Hoover-Dempsey \& Sandler, 1995), with Epstein et al. (2002) and Goodall and Montgomery (2014), offering frameworks for successful parental engagement strategies. However, these proposals do not adequately consider challenges faced by families in challenging circumstances who, in many cases, are termed 'hard to reach'. ${ }^{1}$ Definitions of 'hard to reach' vary in parents degrees of "hard to reach-ness" (Boag-Munroe and Evangelou, 2012, 211) with others avoiding the term, leaving the reader to interpret (Hannon et al., 2003; Sheldon, 2003). A general definition provided by the Health and Safety Executive (HSE) proposes that 'hard to reach parents' are "inaccessible to most traditional and conventional methods for any reason" (HSE, 2004, 8). Synonyms associated with 'hard to reach' imply that it is the family that is 'hard to reach'. For example, families may be described as 'socially

\footnotetext{
${ }^{1}$ The term 'hard to reach' will be presented in apostrophes to emphasise that parents are not assumed to be hard to reach.
} 
excluded' and 'hidden populations' defining the problem within the group itself, not with engagement strategies adopted by institutions (Brackertz, 2007).

From an educational perspective the term 'hard to reach' has been conceptualised by Campbell $(2011,10)$ as parents who have very low levels of engagement with school, do not attend school meetings nor respond to communications and also exhibit high levels of inertia in overcoming perceived barriers to participation (Campbell, 2011). These three elements describe rather than explain why such parents are 'hard to reach'. For example, they fail to explain why parents show low levels of engagement with school. Furthermore, such definitions implicitly blame parents for low levels of engagement and lack of correspondence. These assertions serve to perpetuate the deficit model of poverty and parenting promoted by Payne amongst others, which suggests that individuals in poverty are responsible for their marginalised situation (Payne, 2005). Finally, the use of the word 'inertia' suggests unwillingness to change, making assumptions about the motivations of such individuals.

A more inclusive definition of 'hard to reach' has been provided by Doherty et al. (2004) in a health and welfare programmes context. Here 'hard to reach' is conceptualised as being underrepresented, overlooked and service resistant, acknowledging the reciprocal relationship between services and the individual, highlighting the systematic barriers impacting on participation. As was summarised by Landy and Menna (2006), it's "not what makes individuals hard to reach, but what makes assistance difficult to accept" (180). Here the authors suggest that that using the term "hard to reach' may not be either accurate nor effective in engaging marginalised groups in supportive interventions. For the purpose of this paper, parents will be referred to as under-represented, overlooked and service resistant, recognising the potentially exclusionary practices that the educational system may impose on parents challenging circumstances.

\section{Are 'Hard to Reach' Families also 'Hard to Research'?}

In their systematic review of the literature on 'hard-to-reach' families, Boag-Munroe and Evangelou (2012) outline how the organisational barriers of communication and setting can impact on families' abilities to access services. Communication refers to factors such as culture, language, literacy, 
jargon, difficulty in accessing information about a service, difficulty in asking for help or articulating need and a lack of common understandings across linked practitioners. Organisational barriers to access, associated with setting, include lack of visibility within the community, accidental exclusion of community resources, inappropriate or lack of activities including parents, timing of activities, unwelcoming or inappropriate setting, stigma of being associated with setting, lack of consistency, and poor quality of service. Reasons behind families being 'hard-to-reach' are proposed to be understood as beyond the families' control and which often relate to the personal resources of the family, such as involuntary isolation, health issues and lack of skills.

Challenges facing researchers seeking to work with under-represented, overlooked and service resistant families include effectively ensuring families are informed about how research participation may benefit them (Dodson and Schmalzbauer, 2005). Families may be reluctant to engage due to fear of stigmatisation (Goffman, 1963), concerns about interrogation from government bodies (Dodson, 1998; Soss et al., 2001) or have previous negative experience with authorities (Scott, 1990). In their paper focusing on this issue, Dodson and Schmalzbauer (2005) identified three "habits of hiding" (951), which have emerged from research with families from low-income backgrounds; staying quiet, agreeable talk and selective telling. Such 'habits', driven by fear of criticism, stigmatisation and self-protection, clearly negatively impact on the quality of data generated from any research conducted and guidelines for effective, high quality participatory research were outlined by the authors. These habits, along with others stated by Dobson and Schmalzbauer, like the 'why try effect' (Corrigan et al., 2009), have been associated with reduced engagement in education (Gorski, 2012; Sime and Sheridan, 2014). When working with potentially under-represented, overlooked and service resistant groups the following recommendations have been made to ensure inclusion; describing the sample; finding information sources; finding key contacts; including key contacts as participants in the research; discovering recent or related projects (MacDougall and Fudge, 2001, 121).

Authors have demonstrated strategies to engage families in educational research who may be under-represented, overlooked and service resistant. For example, Sherbert Research (2009) used mini focus groups, interviews and ethnographic observations involving under-represented parents. 
However, no information about recruitment strategies were provided. In another piece, Campbell (2011) proposed to work with 'hard to reach' parents to identify perceived barriers to engagement in their children's education through interviews and focus groups. Participants were recruited through schools which raises questions about the suitability of the sample. When looking at improving parental engagement in education on the whole, Russell and Granville (2005) recruited primarily through schools but adopted a different method for "specifically targeted groups" (Russell and Granville, 2005, 5). They contacted specialist organisations working with these groups (such as those who support asylum seekers), asking the service to make the initial contact with the sample, inviting them to participate. A total of 39 parents identified as 'hard to reach' participated, suggesting that community organisations can act as an effective alternative for non-traditional recruitment in educational research.

When conducting research with Somali families, Jones and Allebone recruited 'hard to reach' parents by being present at school gates and through existing community work (Jones and Allebone, 1999). This was particularly useful as parents could not have been recruited by letter, due to language barriers. This method has been replicated with Bangladeshi parents in the north of England by Crozier and Davies (2007) where interviews were conducted with 591 parents and children. The high attrition rate indicates that recruiting from unconventional methods, based beyond formal organisations and within networks close to parents' culture and community, can prove effective in ensuring families are represented and not overlooked.

Research aiming to engage with 'hard to reach' parents has been discussed, with several different strategies being reviewed. One specific recruitment tool shown to be useful with 'hard to reach' groups is engaging with gatekeepers. Literature surrounding the role of the gatekeeper as an engagement tool will now be discussed.

\section{Gatekeepers as an Effective Recruitment Tool}

The role of the gatekeeper holds great importance when accessing and working with underrepresented parents. A number of guidelines are available for using gatekeepers as a recruitment tool (Atkinson and Flint, 2001; MacDougall and Fudge, 2001; Arcury and Quandt, 1999; Broadhead and 
Rist, 1976). Furthermore, MacDougall and Fudge (2001) present a framework for community recruitment involving three stages (prepare, contact, follow-up) which was "designed to address some of the common recruiting problems, especially when the research deals with sensitive issues and is part of a research agenda that values action and advocacy as a result of, or in association with, research" (MacDougall and Fudge, 2001, 124). The requirement of considerable time and resources was stressed, including the hours spent searching for and negotiating with potential participants, and fitting in with existing meetings, key events, or cultural practices.

The use of gatekeepers has been predominantly seen in the discipline of health (Bonevski et al., 2014; Couch et al., 2014; Kennan et al., 2012; Johnston et al., 2006; Worthington et al., 2005; Penrod et al., 2003; Tross, 2001; Higgins et al., 1996; O'Reilly and Higgins, 1991), youth work (Bengry-Howell and Griffin, 2012; Petersen and Valdez, 2005; Curtis et al., 2004) and social work (Cortis, 2012; Kim, 2011; Abrams, 2010). Gatekeepers have been less well utilised in educational research (Macnab, Visser and Daniels, 2007). When seeking to research young people who were 'hard to find' and out of social welfare systems and provision, gatekeepers have been identified as those professionals with whom researchers must negotiate to gain access to a sample (Macnab, Visser and Daniels, 2007; Daniels and Macnab, 2004).

In their work with groups from a disadvantaged housing estate in the north of England, Emmel et al., (2007) noted the central role gatekeepers can play in accessing 'hard to reach' groups, who can act both as a support and a barrier. The authors proposed a new typology for the continuum of gatekeepers, ranging from formal gatekeepers (such as the police or school staff), to comprehensive gatekeepers (such as supportive agencies or national charities) to informal gatekeepers (individuals offering support who are embedded within the community). It was found that access to the target sample was not possible through formal gatekeepers as there was a relationship of distrust. Formal gatekeepers were perceived as being institutional, enforcing power onto those who were socially excluded and less able to exert their own power. This resulted in individuals being distrustful and hostile, even frightened of formal gatekeepers. Comprehensive gatekeepers provided some access to the sample, but it was evident that the most influential gatekeepers were those who lived and worked within the estate. Where support was given by informal gatekeepers, meaningful connections were 
made between the researchers and participants. However if this support was not given, access became practically impossible. The work of Emmel et al., (2007) clearly highlights not only the key role gatekeepers can play in accessing and researching under-represented groups but also the importance of the most appropriate gatekeeper as being someone embedded within the lived worlds and phenomena forming the focus of the research.

\section{Explaining Gatekeeper Positionality in Research using Social Identity Theory}

The different forms of gatekeepers have been identified, all of whom have varying degrees of efficacy in recruiting participants. This paper will examine the efficacy of the use of formal, comprehensive and informal gatekeepers in educational research, with the results being reflected upon using social identity theory (Tajfel and Turner, 1979), with focus on in-group/out-group identity perceptions.

Within the symbolic interactionist tradition, social identity theory (Hogg and Abrams, 1990; Tajfel, 1982; Tajfel and Turner, 1979) focuses on the categorisation process and objectives of participants in identity negotiations, calling "attention to some of the underlying mechanisms in the symbolic interaction between researchers and participants" (Harrington, 2003, 606). In social identity theory, as in the symbolic interactionist framework in general, individuals' sense of self is taken to be multiplex and composed of both unique and collective aspects negotiated in interaction (Tajfel and Turner, 1979). The collective aspects, based on group memberships, are the focus of the theory. An individual may have as many social identities as group memberships, which may conflict in some ways and thus must be managed, whilst simultaneously serving as an important and flexible resource for making connections with others.

The basis of social identity can include demographic traits, life experiences, hobbies, and so on and is influenced by social context (Ashforth and Mael, 1989). As Hogg and McGarty (1990) state, "social categories are applied in a way which is socially adaptive for the perceiver" (22). Despite its fluidity and context-dependence, the regularities and explanatory power in this theory arise in the form of assumptions about actors' interpersonal objectives. These insights constitute a distinct contribution that social identity theory makes within the symbolic interactionist framework. The basic assumptions are that actors are driven by the following processes: self-categorisation; identity 
enhancement; and similarity/attraction. These processes interact and drive the choice of salient identities as well as shaping the consequences of making any given identity claim.

Possessing a social identity as a member of any given group means accepting at least some group values and norms as well as some degree of conformity to prototypical behaviours (Hogg and Terry, 2000). Groups vary in the amount of latitude they give individuals in conformity to and acceptance of these roles and norms. In this theoretical framework roles function, in part, to signal group identity (Turner, 1999). The key dynamic underlying both roles and social identity in general is that of uncertainty reduction through self-categorisation (Hogg and Terry 2000; Turner, 1999). That is, claiming a social identity and a role within it serves a basic cognitive need by signalling who you are and how you can be expected to behave. Social identity theory construes this as adaptive for both actors and perceivers.

These categorisation processes interact with the desire for identity enhancement. That is, actors not only categorise themselves but attempt to do so in the most positive terms, especially relative to reference groups. As Hogg and Abrams (1990) write, "people generally prefer to seek out positive information about themselves rather than seize the opportunity to learn more about themselves" (22). This applies to organisations and communities, as well as individuals. In practical terms, this means that individuals and groups prefer to interact with others who have been categorised as similar to themselves. Literally, being "like" results in being better-liked (Hogg and Terry, 2000). This is in part because those who are perceived as familiar are assumed to be non-threatening to the group identity. It does not imply that groups always reject people who are different; the key in social identity theory is similarity or enhancement of salient identities. Indeed, it can be identity-enhancing when a high-status individual who is otherwise very different from other group members wants to study the group or shows that he or she shares a salient characteristic that defines the group's identity.

Categorisation processes and the resulting attributions have important consequences for behaviour, particularly for ethnographers seeking access to research sites. The interaction processes underlying social identity theory produce in-group bias, stereotyping, and group cohesion. As a result, those categorised as familiar or similar to the group receive the group's trust, co-operation, and support (Hogg and Abrams, 1990). Those labelled as unfamiliar, different, or unsympathetic to the 
group's identity are likely to be treated with suspicion and hostility, because deviance threatens the group prototype, which is the basis for identification (Hogg and Terry, 2000; Brewer, 1979).

Harrington (2003) applies social psychological theories to unify and expand current conceptions of access in ethnographic research. Through applying social identity theory (Tajfel and Turner, 1979) and self-presentation theory (Rao et al., 1995; Schlenker, 1986; Goffman, 1959, 1956), the author examines the process by which researchers gather data through interpersonal relationships with participants. Focusing on the role of the ethnographic researcher, rather than gatekeeper, Harrington argues "when ethnographers approach a research site, they will be defined in terms of social identity categories salient to participants" (Harrington, 2003, 607) highlighting the role of researcher positionality. Furthermore, access to information can be dictated by "the extent that they are categorised as sharing a valued social identity with participants or as enhancing that identity through their research" (Harrington, 2003, 609). Indeed, "how researchers negotiate their part of this role-assignment process circumscribes their access to data" (Harrington, 2003, 609).

Within the context of this paper, the positionality of formal, comprehensive and informal gatekeepers will be discussed through the lens of social identity theory, building on the work to develop a "a conceptual bridge...to bring together the numerous insights of existing work on the access problem, and to link them to more general social structural processes" (Harrington, 2003, 596). This paper will argue that the stronger group identity salience associated with informal gatekeepers will enhance the recruitment process (as Harrington notes, "[a]nything that signals a valued, salient, and shared identity is interpreted as positive and provides a basis for further relationship", 2003, 616), whereby formal gatekeepers, in being perceived as the out-group, will actually hinder recruitment.

The argument for adopting a social psychological approach to gatekeeper positionality lies in integrating prior approaches to participation recruitment, applying them into a broader context by elaborating a set of interrelated mechanisms and concepts that can be applied to other research contexts. Social psychological theory informs the understanding of psychological processes involved in recruitment, with participants applying an identity to the gatekeeper, along with the implications to their group identity. This theoretical understanding can direct researchers to focus on the most effective means of gaining access in the field, which involves specific kinds of roles with both the 
researcher and gatekeeper (Harrington, 2003, 616). Thus, a social psychological approach to positionality of the gatekeeper helps researchers not only to better define the challenges associated with different views of positionality but also to respond to it in a more skilful and informed way.

This paper provides a unique contribution through the adoption of a community-based methodology to explore parental experience of education, applying Emmel's gatekeeper framework (Emmel, et al., 2007) to classify and examine the efficacy of adopting each type of gatekeeper to recruit service resistant, overlooked and under-represented families. Furthermore, this research provides an original methodological utilisation of community centres (rather than schools), overcoming any potential physical or symbolic barriers parents may perceive in their encounters with schools (Vincent, 2013).

\section{Research Context}

An introduction to research including under-represented, overlooked and service resistant parents has been provided and will be supplemented by a case study example of how engaging with gatekeepers can support this process. The research outlined below was part of a research project to examine factors that impact on families' engagement at primary and secondary schools. The aim of the project was to better understand the perceived barriers faced by families in supporting their children's education, particularly those from areas experiencing significant poverty. Results of the overall project found that families experienced discomfort and difficulty in accessing secondary education, but not primary school. Families attributed this experience to a physical and symbolic distance from secondary school, where they felt they lacked the cultural capital (Bourdieu, 1977) to successfully navigate the secondary school system.

As the literature has shown, location is key in recruiting under-represented, overlooked and service resistant families. It would have been counterproductive to conduct research in accessing education within an educational setting, as this would exclude the families that the research wanted to include. This paper demonstrates a novel methodology in educational research, which is usually applied in social work with 'hard to research' groups (O'Reilly-de Brun et al., 2016; Bonevski et al., 2014) which is embedded in the commitment to removing structural barriers (real or perceived) to 
enable access to participation in research. Specifically, a non-invasive recruitment method through existing community groups was adopted, enabling a more representative sample of families, less hindered by participant bias (the notion that families who engage in school being more likely to engage with research). Focus groups and interviews conducted in community centres were intended to offer a non-threatening, neutral ground for data collection. This original contribution will be presented through a community engagement framework, providing guidance for those seeking to access families who may not traditionally engage well with the school system.

\section{Methodological Approach}

\section{Sample and Recruitment}

Five focus groups were held in the north of England within communities experiencing significant poverty (Ministry of Housing, Communities and Local Government, 2015). Communities included in this study will be referred to as ER, WH, MH, CM and MB. Two other communities were approached but sufficient contact with existing community groups to drive recruitment was not possible.

The study sought to contact families who have never, or no longer engage with their children's education (often referred to as 'hard to reach'). Accordingly, the participant inclusion criteria was as follows: parent, carer or family member; lives within a community experiencing poverty (Ministry of Housing, Communities and Local Government, 2015); cares for a child at secondary school receiving 'Free School Meals'; has no engagement with school, or only engages to complete mandatory administration.

The study sought to recruit families who may be averse to conventional recruitment methods (through schools or other formal organisations). Stakeholder analysis helped to identify key gatekeepers in the community, a tool which has been identified to support recruitment by Sixsmith, Boneham and Goldring (2003) when looking at health services and social capital in a community that faced multiple disadvantages. Following initial consultation with key gatekeepers, participants were recruited through snowball sampling, specifically time-space sampling and respondent-driven sampling (RDS), both of which have been shown to be advantageous in research involving 'hard to 
reach' groups (Semaan, 2010). The main value of snowball sampling is its efficacy as a method for recruiting participants where they are few in number or where some degree of trust is required to initiate contact. Under these circumstances, techniques of chain referral may instil the researcher with characteristics associated with being an insider or group member and this can support access to settings where conventional approaches prove difficult. Often members of such populations may be susceptible to stigmatisation (for example, poverty or mental ill health), impacting on motivation to participate in more formalised studies using traditional research methods. Trust may be developed as referrals are made by informal gatekeepers rather than other more formal methods of identification (Atkinson and Flint, 2001).

A total of 27 adults participated in the focus groups. The ages of participants ranged from 24 years old to 65 years old, and the mean age was 34 years old. The majority of participants were female $(n=24)$, with male participants making up a small proportion of the sample $(n=3)$. A total of 50 parents, carers or family members of children aged between 11-16 years old attended one-to-one semi-structured interviews. This figure is much larger than the conventional 2-10 participants for saturation (Creswell and Miller, 2000). The ages of participants ranged from 29 years old to 64 years old, and the mean age was 39 years old. A majority of participants were females ( $n=34)$, but male participants made a notable contribution to the sample $(n=16)$.

\section{Procedure}

Community groups were identified by utilising local knowledge and stakeholder consultation.

Through meetings with identified gatekeepers (members of staff, volunteers or residents), opportunities were identified to introduce the study to families in a non-threatening way by attending existing groups. All contact with families was facilitated within community centres, which have the advantage of being perceived as being impartial by community members (Bazzano et al., 2015; Blumenthal and DiClemente, 2013). Furthermore, community centres were able to offer flexible accessibility, which has been widely highlighted as a barrier between home-school relations (Vincent, 2013). 
The recruitment process for focus groups and interviews included spending time with members of the community using existing services, introducing the research, and identifying families who fit the inclusion criteria for the study. Potential participants were verbally invited to take part in a focus group and given a participant information sheet, ensuring that all pre-study ethical conditions had been met. This sheet also explained the role of the research and the importance of the study, along with the positive consequences of participating.

The focus groups took place within the community centres and at a time suitable for the participants. Both gatekeepers and participants fully understood that the focus group was separate from any other existing community groups. The groups focused on two explorative questions: 'How easy is it for kids to achieve their ambitions?' and 'what inspires your kids?' One session was held per community which lasted between 40 and 70 minutes, with the first 20-30 minutes acting as an introduction with food and the remaining time being the focus group. Group sizes ranged from 0 to 9 $($ median $=6 ;$ mean $=6.25)$ with two medium sized groups $(7$ and 9$)$ and two smaller groups $(3$ and 4$)$. There is evidence advising optimal sizes for focus groups, with some suggesting 'middle-sized' groups provide the best quality of ideas (Ruyter, 1996) and others proposing that 'small-sized' groups of 4-6 to be productive since they encourage all members to take part in the discussion (Prince and Davies, 2001). Such small groups, or what Krueger (1994) called "mini-focus groups" (p.17), have also been advocated when participants have specialised knowledge and experiences to discuss within the group, which could be argued was the case with the sample in this study (Onwuegbuzie et al., 2009).

Semi-structured interviews were used to discuss key items identified in focus groups and were again conducted in community centres. An interview schedule was generated, informed by the emergent themes of the focus groups. The main areas of focus in the interview schedule were child's interests and perception of education; participant attitudes and values surrounding education; participant experience of education as a child; participant experience of primary education as a parent or carer; participant experience of child's school transition; and participant experience of secondary education as a parent or carer. Questions were a mix of open and closed questions and being a semistructured interview had scope to explore themes that emerged during the interview. As with the focus 
groups, interviews took take place in community centres and at a time suitable for the participants. Interviews lasted between 30 and 80 minutes. A field journal was maintained throughout the data collection period and was used to inform this report. Considering the nature of the target group, a total sample of 77 participants demonstrates that with careful consideration, overlooked populations can be effectively accessed and recruited for research purposes.

\section{Data Explication}

In order to organise the data prior to explication, written transcripts were analysed using NVivo. Transcripts were coded according to emerging themes, such as positive experiences of primary school. These were further broken down in more detail, such as feeling confident talking to primary school teachers. Following this understanding, the codes (based on Bourdieu's theory of social reproduction, 1974) were introduced in an attempt to apply Bourdieu's habitus to the experience of families. Key direct quotations were then extrapolated from the data and used to frame the structure of the results section.

The research discussed in this paper adopted Relph's phenomenology of place (Relph, 1976), using Husserl's phenomenological reduction in suspending one's assumptions about an individual's interactions and interpretation of a given place (Husserl, 1901). As stated by Husserl, "phenomenological explication does nothing but explicate the sense this world has for us all, prior to any philosophizing, and obviously gets solely from our experience- a sense which philosophy can uncover but never alter" (Husserl, 1960, 151). In other words, families' descriptions of their contact with school is of value because it is their own interpretations of the world. For example, if a mother reports that all secondary teachers are cold and aloof towards her, this would not be taken for granted. Rather, this would be seen as a subjective experience resulting in a degree of 'outsideness' (Relph, 1976). It is through this process of explication that a phenomenological understanding of families' experiences of primary and secondary education was made, free from any taken-for-granted assumptions about the social world of families.

\section{Reflective Findings: Gatekeeper Positionality in Inclusive Research}


The research design and methodology outlined above provides a framework to successfully engage and involve under-represented families in educational research. A reflective account will now be given, providing insights into the experience of conducting this community-based methodology. This reflective account refers to the experience of families accessing the research, rather than accessing the education system, which was the overarching theme the research project. These reflections are supported by accounts from families that emerged during the data collection to help illustrate the lived experience of families in accessing such gatekeepers.

\section{Positionality of Services}

At first glance, the methodology adopted within each community looks identical, targeting existing groups within community centres situated in areas experiencing significant poverty (Ministry of Housing, Communities and Local Government, 2015). However, the centres varied, particularly in terms of organisations operating within the centre and positionality of staff. As an example, the table below compares the core features of ER that had the highest attendance, with WH which despite two different recruitment drives, failed to engage any families from the community:

\section{(Insert table 1 here)}

The above table suggests that services offered to families at WH aim to address 'need' or offer support, whereas ER provides a wealth of enrichment activities for and by community. Furthermore, the more informal the centre and staff, the busier the groups were. This suggests two things, firstly that there is a stronger in-group salience where services are perceived as informal and gatekeepers being from within the community. Secondly, the formal services at WH suggest a power imbalance, imposing a deficit ideology to the community who need the support of external services as their community lacks the ability to support itself. The comparison between these two centres clearly demonstrates the potentially pivotal role of perceived service positionality in accessing underrepresented families. A core feature of this, the positionality of the gatekeeper, will now be discussed in more detail. 


\section{Positionality of Gatekeepers}

Before attempting to build rapport with families, considerable time was invested to build an effective relationship with relevant gatekeepers, gaining the vital support of the people who have the most contact with families. Gatekeepers had various roles in the community with differing levels of perceived proximity to the communities in which they worked, ranging from community volunteers who lived within the communities to members of staff who worked for a formal organisation and did not live in the area.

By adopting the typology of the gatekeeping continuum (Emmel et al., 2007) the table below demonstrates how the positionality of the gatekeeper can have a significant influence on participant recruitment rates:

\section{(Insert table 2 here)}

These figures clearly demonstrate the positive impact that informal gatekeepers can have when working with 'hard to reach' families, and how ineffective formal gatekeepers can be, such as schools and child services. From a social identity theory perspective it can be seen that informal gatekeepers had a strong in-group salience to participants, aiding recruitment. Conversely, the formal gatekeepers were perceived as out-group members by participants, hindering recruitment.

The groups that had the highest attendance (MH and ER) had the operational support of a key community gatekeeper. These gatekeepers worked or volunteered for the community organisation and lived within the community, thus bridging the gap between organisation and the community (Putnam, 2000). Both gatekeepers demonstrated strong links within their community, with a deep connection with those who lived there and shared history. The gatekeepers supported recruitment by offering consultation in the way of promotion and, by verbally encouraging community members to participate, reducing scepticism about talking to someone from the out-group.

From the perspective of social identity theory, informal gatekeepers, those who live within the community, through families' self-categorisation, perceive a shared group membership with the 
gatekeepers. This group membership, which may take the form of being female, a mother or living in the same neighbourhood, creates a shared social identity which, for example, builds trust, cooperation, and support (Hogg and Abrams, 1990). Informal gatekeepers are perceived to share the same norms of the families; these norms may include a perceived shared interest in the welfare of the community in which the research is taking place. Furthermore, the mere presence of research being conducted within the community by a self-categorised out-group will reinforce any community group identity salience, whereby similarities of those group members are emphasised and group members are looked upon more favourably.

Informal gatekeepers, mainly in the case of grass-roots community centres, were frequently cited by families as playing a significant role in their lives. This role tended to centre around support responding to their children's needs and or supporting families with overcoming other barriers, such as debt. For example, Leanne reflects on how her local community centre helped her son following his removal from mainstream education:

[The community centre has] been helping out here, she's doing a lot with him. Then he's doing things at home with me and he's getting out, he's doing things like the [community group] and things like that. He's getting to be with other people and stuff. He's been fantastic, honestly, the best thing.

Here, Leanne refers to the community centre to which she is part of, indicating that she identifies as being part of the community centre social group. Furthermore, Beverley reflects on her feelings of belonging with her community centre, "I think on the whole the community centre is a fantastic place and the people that they get in are the same network of people. I'm very fortunate because I have a connection.” Discussions surrounding social networks and connections particularly highlight Beverley's group identification with her local community centre and comfort in using their services.

In addition to the traditional informal gatekeeper, participants acted as gatekeepers in their use of RDS, serving as an invaluable recruitment partner in gaining access to families who are underrepresented. This sampling method goes further to support the application of social identity theory to explore the use of community gatekeepers in research. As members of the perceived in-group lead recruitment it could be argued that the self-categorised group members perceived a stronger group salience, felt more positively towards these families and thus were more willing to engage with the 
research. This further highlights the key role those embedded within the community can have with recruitment, in promoting trust and status within target populations.

One comprehensive gatekeeper featured in this research (MP), recruiting four parents to participate in focus groups. This gatekeeper worked for a housing association, and the boundaries between her and the parents were much more apparent than when informal gatekeepers supported recruitment. Even though her sister lived in the neighbourhood, she was not as strongly identified as belonging to their in-group. Applying social identity theory, it can be suggested that parents were unsure about the gatekeepers' group identity, working for an organisation which, as much as it was physically based in the community, was not entirely embedded within the community. The norms and motivations of this group may not have been perceived as being in alignment with parents' selfcategorised representative group and thus some scepticism may have been made when considering research participation. However, some trust was displayed by the four participating parents, suggesting that comprehensive gatekeepers can successfully recruit families considered 'hard to reach' in research. Parents provide examples of accessing comprehensive gatekeepers, such as charities and health care providers in times of crisis or to help overcome a behaviour or health issue. For example, Jade describes how she has accessed "CAMHS and [a family centre], they're all chipping in been trying to help her make her better, self-confidence and stuff." Another mother, Lisa, describes how a local family centre played a central role in her social networks locally "I come to some groups at the [children's centre] but other than that I don't get out much I spend a lot of time looking after the house.” These examples illustrate how services which have a specific focus (for example, mental health, young mothers) can provide access to hidden populations and also provide wider benefits for so called 'hard to reach' parents. Parents' accounts of comprehensive gatekeepers tended to be neutral, without any clear group identification.

The potentially detrimental impact of the formal gatekeeper was made apparent when no families attended or participated in both WH focus groups. Within their community centre, WH hosts five different organisations that operate on a regular basis and all organisations supported and publicised the research. This highlights that merely being physically present within a community does not necessarily challenge the in-group/out-group barriers perceived by members of the community. 
Following this unsuccessful recruitment strategy, a second strategy was developed using the local primary school to recruit families through distributing fliers to all pupils. This again resulted in nonattendance, supporting the argument that formal institutions, with formal gatekeepers, may not serve as an effective recruitment tool for under-represented groups. From the perspective of social identity theory statutory organisations, such as schools, are self-categorised as being different and distant from the groups families identify with. Norms and values are perceived as being different, and therefore trust is limited, impacting negatively on engagement in research participation. Focus groups and interviews revealed a symbolic distance from formal gatekeepers. For example, schools were often referred to as the 'other', with Gemma providing an illustrative example of her discomfort in a school meeting:

You're sitting there and you're trying to tell them something, they're looking down their nose at you. And that's what makes me mad. I think they think 'because she's a single parent...', and that's what makes it worse, I'm no different from anybody else, but a lot of people don't see it like that.

This account suggests that structures like schools are perceived by parents as being beyond their selfcategorised group, resulting in an out-group identification and thus feeling threatened and resistive.

By examining recruitment rates using the gatekeeper continuum it is clear that their symbolic presence in a community is significant, more important than simply being physically present. The symbolic interactionist approach exposed by social identity theory provides a useful framework to explain the efficacy of different gatekeepers in recruiting a group who may be under-represented, overlooked and service resistant within the realms of educational research.

\section{Discussion: A Community Engagement Framework for Under-Represented, Overlooked and}

\section{Service Resistant Families}

As researcher reflections and accounts from families have shown, social identity theory has clear implications for gatekeeper positionality in inclusive educational research. This distinctive transdisciplinary approach to recruiting and listening to families who may struggle to engage with schools serves to provide guidance to other researchers who may wish to understand the educational experiences of those who are often excluded from traditional research methods, such as surveys or 
school based research. The application of a methodology primarily used in health, youth work and social work acknowledges how social identities impact on engagement and the resulting community engagement framework for educational research provides guidance on how to overcome the organisational barriers of communication and setting (Boag-Munroe and Evangelou, 2012).

The use of social identity theory encourages researchers to reflect on the symbolic interactions between people and the ways in which it can impact on research participation (Hogg and McGarty, 1990). Rooted in the ways individuals see themselves as group members, self-categorisation has been suggested to impact on families' participation research (Hogg and Terry, 2000), with few similarities being perceived between themselves and formal gatekeepers, and more with informal. Having a perceived clear role in the community may have served to enhance families' group identification with the community centres (Hogg and Terry, 2000; Turner, 1990), something that schools may wish to consider when developing parental engagement programmes and taking into account group bias, stereotyping and group cohesion (Hogg and Abrams, 1990). In terms of gatekeeper positionality in accessing research participation, the current paper adds to Harrington's (2003) argument that social categorisation plays a key role in the recruitment and engagement in research participants.

The observations and reflections of applying social identify theory to Emmel's gatekeeper continuum have clear implications for policy, practice and research. The table below provides stepby-step guidance of how to successfully recruit and engage with overlooked, under-represented or service resistant groups:

(Insert table 3 here)

Whilst frameworks like the above serve as useful guidelines, researchers must avoid a reductionist approach and consider the nuances of a given population when developing recruitment strategies.

\section{Implications}


The results presented in this paper complement existing literature surrounding the use of alternative methods in engaging families who are under-represented, overlooked and service resistant in educational research (Sime and Sheridan, 2014; Boag-Munroe and Evangelou, 2012; Gorski, 2012; Campbell, 2011; Sherbert Research, 2009; Crozier and Davies, 2007; Dodson and Schmalzbauer, 2005; Russell and Granville, 2005; Soss et al., 2001; Jones and Allebone, 1999; Dodson, 1998; Scott, 1990). The efficacy of the recruitment strategies discussed in this paper reveal insights into factors which influence parental engagement, adding to the field and existing frameworks (Goodall and Montgomery, 2014; Epstein et al., 2002). Indeed, as Gemma's account clearly shows, researchers need to be cognisant of the previous contact parents have had with schools in choosing sites in which to conduct research. Furthermore, the recruitment strategy builds on Emmel's gatekeeper continuum (Emmel et al., 2007), demonstrating its applicability in educational research and the role of informal gatekeepers in recruiting under-represented, overlooked and service resistant families.

Results were interpreted through Tajfel and Turner's social identity theory (Tajfel and Turner, 1979), a predominant theory in social psychology. This paper goes to further strengthen the theory's use, beyond interpreting results to applying it to a methodological standpoint. Through using social categorisation and applying the process of group identity to the processes involved in recruiting under-represented, overlooked and service resistant families, potential barriers to participation can be understood. Furthermore, these barriers can be overcome through the adoption of the community engagement framework introduced in this paper, guiding research seeking to involve those who are resistant to engage with traditional recruitment methods in educational research.

The methodologies undertaken in this research demonstrates that parents and families who do not engage in education may, in some cases, be willing to participate in educational research. By carefully considering a schools' positionality in how it is viewed by the community, policy could help to guide schools to develop their engagement strategies. In the UK, the Ofsted Inspection Handbook guides inspectors when conducting mandatory visits, which include parental and community engagement. The findings from this paper enhance the evidence surrounding strategies to effectively engage with parents and families within their own communities. These case studies can inform policy 
surrounding what is expected from schools in engaging with parents and families who may be marginalised in education.

The results generated have widely applicable implications in educational practice. In the UK Ofsted monitors schools' efforts to engage parents, investigating "how well all staff work with parents, engage them in their children's learning and keep parents informed about their children's achievements and progress" (Ofsted, 2015). In setting out guidelines to promote engagement with 'hard to reach' families, this paper offers a framework to support educational practitioners in engaging with families through considered community approaches. Furthermore, the results indicate that recruiting community gatekeepers as engagement staff (e.g. support staff, attendance officers), may promote a more positive engagement with school, with in-group/out-group boundaries between home and school being blurred. These results support the work of previous community based educational family interventions which found the most valuable way to support 'hard to reach' groups was to develop relationships and gain trust through working with community leaders (Parsons et al., 2003, 41-42). Collectively, this suggests that informal gatekeepers have a significant impact in participation in educational activities.

In addition to implications for schools, families can benefit from engaging in educational research. Through having better access to research, families can become agents for change by being involved in impactful work which could potentially benefit their children. Research suggests that participation can increase confidence and self-efficacy, promoting a range of benefits to both parent and child (Dodson and Schmalzbauer, 2005). Furthermore, services may better understand families and consequently lead to service improvement.

\section{Limitations}

One group of under-represented, overlooked and service resistant parents were unable to engage in the research, and reasons for this are not known. More research is needed to develop further understandings of why some people are not able to participate in research. Alternative recruitment strategies may have been useful to engage with communities to dispel the perceived group categorisation of the research. These recruitment strategies include using social media sites, such 
Facebook, where informal gatekeepers have the opportunity to share research information. Indeed, there is evidence supporting the use of social media and web-based promotion in working with marginalised groups, including parents (Wasserman and Zwebner, 2017; Jaén et al., 2014; Bouffard, 2006).

The role and impact of the three types of community gatekeeper in recruiting underrepresented, overlooked and service resistant families has been provided exclusively from a researcher's perspective. This view may be subject to certain biases on behalf of the researcher, with assumptions about the families. In spite of reflective efforts to ensure pure bracketing, the process of abandoning one's assumptions (Husserl, 1913), this position can be difficult to achieve, leading to interference in the interpretation of the data. Moreover, it could be argued that the researcher holds an unfair position of power, which may impact the on interpretation of the data. This is further exacerbated by families not being consulted about the reflective accounts detailed in this paper. More research is needed to work directly with groups considered under-represented, overlooked and service resistant to gain insight into their experiences and interpretations of different recruitment methods.

\section{Conclusion}

The purpose of this paper was to demonstrate that as much as families may be 'hard to reach' to schools, they are not necessarily hard to research. The methodology adopted was successful in gaining access to 'hard to reach' families. By facilitating informal focus group sessions within community centres familiar to the participants, families felt able to attend and to share their views. The fundamental role of informal gatekeepers has been highlighted in effectively engaging with these groups through perceived belonging in self-categorised groups. The uninviting influence of formal gatekeepers was also demonstrated, through being perceived as being a distinct out-group member, which impacted on trust. The methodologies outlined in this paper serve to promote an inclusive representational approach to working with socially excluded families in education. The innovative integration of a social work methodology with social identity theory provides a framework in which researchers can not only understand the possible reasons why some families may be unwilling or unable to participate in educational research, but also provide some possible solutions to removing as 
many perceived barriers as possible. This surely is the ambition of any research seeking to understand the experiences of those potentially marginalised in education, supporting inclusion and participation wherever possible.

\section{References}

Abrams, L. S. 2010. "Sampling 'hard to reach' populations in qualitative research: The case of incarcerated youth.” Qualitative Social Work 9 (4): 536-550. doi:10.1177/1473325010367821.

Arcury, T. A., and Quandt, S. A. 1999. "Participant recruitment for qualitative research: A site-based approach to community research in complex societies." Human Organization 58 (2): 128-133. dio:10.17730/humo.58.2.t5g838w7u1761868

Ashforth, B. E., and Mael, F. 1989. "Social identity theory and the organization.” Academy of Management Review 14 (1): 20-39.

Atkinson, R and Flint, J, 2001. “Accessing Hidden and Hard-to-Reach Populations: Snowball Research Strategies.” Social Research Update 28 (1): 93-108.

Bazzano, A., Wolfe, C., Zylowska, L., Wang, S., Schuster, E., Barrett, C., and Lehrer, D. 2015. "Mindfulness based stress reduction (MBSR) for parents and caregivers of individuals with developmental disabilities: A community-based approach." Journal of Child and Family Studies 24 (2): 298-308. dio:10.1007/s10826-013-9836-9

Bengry-Howell, A., and Griffin, C. 2012. "Negotiating access in ethnographic research with "hard to reach' young people: establishing common ground or a process of methodological grooming?" International Journal of Social Research Methodology 15 (5): 403-416. dio: $10.1080 / 13645579.2011 .600115$

Blumenthal, D. S., and DiClemente, R. J. ed. 2013. Community-based participatory health research: Issues, methods, and translation to practice. Springer Publishing Company.

Boag-Munroe, G., and Evangelou, M. 2012. "From hard to reach to how to reach: A systematic review of the literature on hard-to-reach families." Research Papers in Education 27(2): 209239. dio:10.1080/02671522.2010.509515 
Bonevski, B., Randell, M., Paul, C., Chapman, K., Twyman, L., Bryant, J., Brozek, I. and Hughes, C. 2014. "Reaching the hard-to-reach: a systematic review of strategies for improving health and medical research with socially disadvantaged groups." BMC Medical Research Methodology 14 (1): 14-42. doi:10.1186/1471-2288-14-42

Bouffard, S. M. 2006. “"Virtual” Parental Involvement: The Role of the Internet in Parent-School Communication" PhD diss., Duke University.

Bourdieu, P. 1974. "The School as a Conservative Force: Scholastic and Cultural Inequalities.” Contemporary Research in the Sociology of Education 32: 46.

Bourdieu, P. 1977. "Outline of a Theory of Practice" (Vol. 16). Cambridge University Press.

Brackertz, N. 2007. "Who is hard to reach and why." Institute of Social Research Working Paper, Swinburne University of Technology Institute of Social Research, Victoria. Accessed 9 May 2018. http://www. sisr net/publications/0701brackertz. Pdf.

Brewer, M. B. 1979. "In-group bias in the minimal intergroup situation: A cognitive-motivational analysis.” Psychological Bulletin 86 (2): 307-324. doi:10.1037/0033-2909.86.2.307.

Broadhead, R. S. and Rist, R. C. 1976. "Gatekeepers and the Social Control of Social Research." Social Problems 23 (3): 325-336. doi:10.2307/799778

Burrows, D., and Kendall, S. 1997. "Focus groups: what are they and how can they be used in nursing and health care research?" Social Sciences in Health 3: 244-253.

Campbell, C. (2011). "How to involve hard-to-reach parents: encouraging meaningful parental involvement with schools". National College for School Leadership. Accessed on 9 May 2018 http://dera.ioe.ac.uk/12136/1/download\%3Fid=156367\&filename=how-to-involve-hard-toreach-parents-full-report.pdf

Corrigan, P. W., Larson, J. E., and Ruesch, N. 2009. "Self-stigma and the "why try" effect: impact on life goals and evidence-based practices." World Psychiatry 8 (2): 75-81. doi:10.1002/j.20515545.2009.tb00218.x

Cortis, N. 2012. “Overlooked and under-served? Promoting service use and engagement among 'hardto-reach' populations." International Journal of Social Welfare 21 (4): 351-360. doi:10.1111/j.1468-2397.2011.00825.x 
Couch, J., Durant, B., and Hill, J. 2014. "Uncovering marginalised knowledges: Undertaking research with hard-to-reach young people." International Journal of Multiple Research Approaches 8 (1): 15-23. doi:10.5172/mra.2014.8.1.15

Creswell, J. W., and Miller, D. L. 2000. "Determining validity in qualitative inquiry." Theory Into Practice 39 (3): 124-130. doi:10.1207/s15430421tip3903_2

Crozier, G. and Davies, J. 2007. "Hard to reach parents or hard to reach schools? A discussion of home-school relations, with particular reference to Bangladeshi and Pakistani parents." British Educational Research Journal 33 (3): 295-313. doi:10.1080/01411920701243578

Curtis, K., Roberts, H., Copperman, J., Downie, A., and Liabo, K. 2004. “'How come I don't get asked no questions?' Researching 'hard to reach' children and teenagers.” Child \& Family Social Work 9 (2): 167-175. doi:10.1111/j.1365-2206.2004.00304.x

Dodson, L. 1998. Don't call us out of name: The untold lives of women and girls in poor America. Boston: Beacon Press.

Dodson, L., and Schmalzbauer, L. 2005. "Poor mothers and habits of hiding: Participatory methods in poverty research.” Journal of Marriage and Family 67 (4): 949-959. doi:10.1111/j.17413737.2005.00186.x

Doherty, P., Stott, A. and Kinder, K. 2004. Delivering Services to Hard to Reach Families in On Track Areas: Definitions, Consultation and Needs Assessment, Home Office Development and Practice Report. Accessed on 9 May 2018 http://webarchive.nationalarchives.gov.uk/20100612150419/http://rds.homeoffice.gov.uk/rds/ pdfs2/dpr15.pdf

Emmel, N., Hughes, K., Greenhalgh, J. and Sale, A. 2007. “Accessing Socially Excluded People: Trust and the Gatekeeper in the Researcher-Participant Relationship.” Sociological Research Online, 12 (2):1-13. doi.org/10.5153/sro.1512

Epstein, J. L., Sanders, M. G., Simon, B. S., Salinas, K. C., Jansorn, N. R., and Van Voorhis, F. L. 2002. School, family, and community partnerships: Your handbook for action. Corwin Press.

Goffman, E. 1956. "The nature of deference and demeanor.” American Anthropologist 58 (3): 473 502. 
Goffman, E. 1959. The Presentation of Self. In. Butler, Bodies that Matter. Penguin: London.

Goffman, E. 1963. Behavior in public place. Glencoe: New York.

Goodall, J., and Montgomery, C. 2014. "Parental involvement to parental engagement: a continuum." Educational Review 66 (4): 399-410. doi:10.1080/00131911.2013.781576

Gorski, P. C. 2012. "Perceiving the problem of poverty and schooling: Deconstructing the class stereotypes that mis-shape education practice and policy." Equity \& Excellence in Education 45 (2): 302-319. doi:10.1080/10665684.2012.666934

Hannon, P., Pahl, K., Bird, V., Taylor, C., and Birch, C. 2003. Community-focused provision in adult literacy, numeracy and language: an exploratory study. National Research and Development Centre: London

Harrington, B. 2003. "The Social Psychology of Access in Ethnographic Research.” Journal of Contemporary Ethnography 32 (5): 592 - 625. doi:10.1177\%2F0891241603255677

Health and Safety Executive. 2004. "Successful Interventions with Hard to Reach Groups.” Accessed on 15 February 2016. www.hse.gov.uk/research/misc/hardtoreach.pdf

Higgins, D. L., O'Reilly, K., Tashima, N., Crain, C., Beeker, C., Goldbaum, G., Elifson C.S., Galavotti C., and Guenther-Grey C. 1996. "Using formative research to lay the foundation for community level HIV prevention efforts: an example from the AIDS Community Demonstration Projects." Public Health Reports, 111 Suppl 1: 28-35.

Hogg, M. A., and Abrams, D. 1990. "Social motivation, self-esteem and social identity." In Social Identity Theory: Constructive and Critical Advances (pp 28-47). Springer-Verlag Publishing.

Hogg, M. A., and McGarty, C. 1990. "Self-categorization and social identity." in Social Identity Theory: Constructive and Critical Advances (pp 10-27). Springer-Verlag Publishing.

Hogg, M. A., and Terry, D. I. 2000. "Social identity and self-categorization processes in organizational contexts." Academy of Management Review 25 (1): 121-140. doi:10.5465/amr.2000.2791606

Hoover-Dempsey, K. V., and Sandler, H. M. 1995. "Parental involvement in children's education: Why does it make a difference?" Teachers College Record 97 (2): 310-331. 
Husserl, E. 1901: Logische Untersuchungen. Zweiter Theil. Untersuchungen zur Phänomenologie und Theorie der Erkenntnis. Halle: Max Niemeyer.

Husserl, E. 1960. "Cartesian meditations, trans.” Dorion Cairns (The Hague: Martinus Nijhoff). Jaén, M. M., Moreno, J. R., Moreno, J. C., and Navío, E. P. 2014. "Social Networks and Parent Teacher Meetings: A Question That Can’t Wait.” EDULEARN14 Proceedings: 202-212.

Johnston, L. G., Sabin, K., Hien, M. T., and Huong, P. T. 2006. “Assessment of respondent driven sampling for recruiting female sex workers in two Vietnamese cities: reaching the unseen sex worker.” Journal of Urban Health 83 (1): 16-28.

Jones, L., and Allebone, B. 1999. "Researching 'hard-to-reach' groups: the crucial role of the research associate.” International Journal of Inclusive Education 3 (4): 353-362. doi:10.1080/136031199284986

Kennan, D., Fives, A., and Canavan, J. 2012. “Accessing a hard to reach population: reflections on research with young carers in Ireland." Child \& Family Social Work 17 (3): 275-283.14. doi:10.1111/j.1365-2206.2011.00778.x

Kim, Y. 2011. "The pilot study in qualitative inquiry: Identifying issues and learning lessons for culturally competent research.” Qualitative Social Work 10 (2): 190-206. doi: $10.1177 \% 2 \mathrm{~F} 1473325010362001$

Krueger, R. A. 1994. Focus Groups: A Practical Guide for Applied Research, Thousand Oaks, Sage Publications: CA.

Landy, S., and Menna, R. 2006. "An evaluation of a group intervention for parents with aggressive young children: Improvements in child functioning, maternal confidence, parenting knowledge and attitudes." Early Child Development and Care 176 (6): 605-620. doi:10.1080/03004430500147425

MacDougall, C., and Fudge, E. 2001. "Planning and recruiting the sample for focus groups and indepth interviews." Qualitative Health Research 11 (1): 117-126. doi:10.1177\%2F104973201129118975 
Macnab, N., Visser, J., and Daniels, H. 2007. "Desperately seeking data: Methodological complications in researching 'hard to find' young people." Journal of Research in Special Educational Needs 7 (3): 142-148. doi:10.1111/j.1471-3802.2007.00091.x

Ministry of Housing, Communities and Local Government (2015). Indices of Multiple Deprivation Explorer. Accessed on 9 May 2018. http://dclgapps.communities.gov.uk/imd/idmap.html O’Reilly-de Brún, M., de Brún, T., Okonkwo, E., Bonsenge-Bokanga, J. S., Silva, M. M. D. A., Ogbebor, F., Mierzejewska, A., Nnadi, L., van Weel-Baumgarten, E., van Weel, C., van den Muijsenbergh, M., and MacFarlane. A. 2016. "Using Participatory Learning \& Action Research to Access and Engage with 'Hard to Reach' Migrants in Primary Healthcare Research.” BMC health services research 16 (1): 25.

Ofsted (2015). School Inspection Handbook. Accessed on 9 May 2018.

https://www.gov.uk/government/publications/school-inspection-handbook-from-september$\underline{2015}$

Onwuegbuzie, A. J., Dickinson, W. B., Leech, N. L., and Zoran, A. G. 2009. “A qualitative framework for collecting and analyzing data in focus group research." International Journal of Qualitative Methods 8 (3): 1-21. doi:10.1177\%2F160940690900800301

O'Reilly, K. R., and Higgins, D. L. 1991. “AIDS Community Demonstration Projects for HIV prevention among hard-to-reach groups.” Public Health Reports 106 (6): 714-720.

Parsons, C. Austin, B., Bryan, H., Hailes, J., and Stow, W. 2003. On Track Thematic Report: Community \& Schools Engagement, Department of Education and Skills Research Report RR474. Accessed on 19 December 2017. http://webarchive.nationalarchives.gov.uk/20130404090639/https://www.education.gov.uk/pu blications/eOrderingDownload/RR474.pdf

Payne, R. K. 2005. A Framework for Understanding Poverty. Highlands, TX: aha! Process.

Penrod, J., Preston, D. B., Cain, R. E., and Starks, M. T. 2003. "A discussion of chain referral as a method of sampling hard-to-reach populations.” Journal of Transcultural Nursing 14 (2): 100-107. doi:10.1177\%2F1043659602250614 
Petersen, R. D., and Valdez, A. 2005. "Using snowball-based methods in hidden populations to generate a randomized community sample of gang-affiliated adolescents." Youth Violence and Juvenile Justice 3 (2): 151-167. doi:10.1177\%2F1541204004273316

Prince, M., and Davies, M. 2001. "Moderator teams: an extension to focus group methodology." Qualitative Market Research: An International Journal 4 (4): 207-216.

Putnam, R. D. (2000). “Bowling alone: America's declining social capital.” In Culture and Politics (pp. 223-234). Palgrave Macmillan: New York.

Rao, A., Schmidt, S. M., and Murray, L. H. 1995. "Upward impression management: Goals, influence strategies, and consequences." Human Relations 48 (2): 147-167.

Relph, E. 1976. Place and Placelessness. London: Pion.

Russell, K., and Granville, S. 2005. Parents' Views on Improving Parental Involvement in Children's Education: Executive Summary and Conclusions. Scottish Executive. Accessed on 5 May 2018 http://www.gov.scot/Publications/2005/03/20759/53608

Ruyter, K. D. 1996. "Focus versus nominal group interviews: a comparative analysis.” Marketing Intelligence \& Planning 14 (6): 44-50.

Sammons, P., Toth, K., and Sylva, K. 2016. How Aspirations and Academic Self Concept Shape Young People's Outcomes. London, England: Sutton Trust. Accessed on 5 August 2017 http://www.suttontrust.com/wp-content/uploads/2016/06/EPPSE-final-Believing-in-Better.pdf

Schlenker, B. R. 1986. "Self-identification: Toward an integration of the private and public self." In Public Self and Private Self (pp. 21-62). Springer: New York, NY.

Scott, D. 1990. "Practice wisdom: The neglected source of practice research." Social Work 35 (6): 564-568. doi:10.1093/sw/35.6.564

Semaan, S. 2010. "Time-Space Sampling and Respondent-Driven Sampling with Hard-To-Reach Populations." Methodological Innovations Online 5 (2): 60-75. doi:10.4256\%2Fmio.2010.0019

Sheldon, S. B. 2003. "Linking school-family-community partnerships in urban elementary schools to student achievement on state tests." The Urban Review 35 (2): 149-165. 
Sherbert Research. 2009. "Parents as Partners: 'Harder to Engage' Parents, Research, Report DCSFRR111” Department for Education. Accessed on 9 May 2018. http://dera.ioe.ac.uk/11166/1/DCSF-RR111.pdf

Sime, D., and Sheridan, M. 2014. “'You want the best for your kids': improving educational outcomes for children living in poverty through parental engagement." Educational Research, 56 (3): 32-342. doi:10.1080/00131881.2014.934556

Sixsmith, J., Boneham, M., and Goldring, J. E. 2003. “Accessing the Community: Gaining Insider Perspectives From the Outside." Qualitative Health Research 13 (4): 578-589. doi: $10.1177 \% 2 \mathrm{~F} 1049732302250759$

Soss, J., Schram, S. F., Vartanian, T. P., and O'Brien, E. 2001. "Setting the terms of relief: Explaining state policy choices in the devolution revolution." American Journal of Political Science 45 (2): $378-395$

Tajfel, H. (1982). Social psychology of intergroup relations. Annual Review of Psychology, 33(1), 139.

Tajfel, H., and Turner, J. C. 1979. “An integrative theory of intergroup conflict.” In W. G. Austin, \& S. Worchel (Eds.), The social psychology of intergroup relations (pp. 33-37). Brooks/Cole:Monterey, CA.

Tross, S. 2001. "Women at heterosexual risk for HIV in inner-city New York: Reaching the hard to reach.” AIDS and Behavior 5 (2): 131-139.

Turner, J. C. 1999. "Some current issues in research on social identity and self-categorization theories." Social identity: Context, Commitment, Content 3 (1): 6-34.

Vincent, C. 2013. Parents and teachers: Power and participation. Routledge. London.

Wasserman, E., and Zwebner, Y. 2017. "Communication between Teachers and Parents using the WhatsApp Application.” International Journal of Learning, Teaching and Educational Research 16 (12). doi:10.26803/ijlter.16.12.1 
Worthington, C., Myers, T., O'Brien, K., Nixon, S., and Cockerill, R. 2005. "Rehabilitation in HIV/AIDS: development of an expanded conceptual framework." AIDS Patient Care \& STDs, 19 (4): 258-271. doi:0.1089/apc.2005.19.258 